\title{
Las imágenes teatrales de Tadeusz Kantor y el teatro surrealista español El caso de Wielopole, Wielopole
}

\begin{abstract}
Resumen:
En la primera parte del presente artículo se hace un resumen de los trabajos cuyo objetivo es el análisis de la relación que unía a Tadeusz Kantor con la cultura española que en su mayoría se centran en los motivos pictóricos españoles en la obra tanto plástica como teatral del artista polaco. Más tarde se compara el teatro imposible de García Lorca con el teatro imposible de Kantor a nivel temático, pero sobre todo a nivel estético centrándose en el lugar que en ambos escenarios ocupan los objetos que aparecen abstraídos del sistema de signos establecido y se vuelven incomprensibles e insólitos. En concreto, se comparan dos objetos de Wielopole, Wielopole y de El Público, respectivamente. Se trata de dos camas giratorias que al mismo tiempo son camas mortuorias. Se analiza su simbolismo y su significación en sendas escenas y obras.
\end{abstract}

Palabras claves: Kantor, Garía Lorca, teatro, objetos surrealistas, doble

\begin{abstract}
:
Theatrical Images of Tadeusz Kantor and the Spanish Surrealist Theater. The Case of Wielopole, Wielopole

The first part of the article is a summary of the works whose objective is the analysis of the relation that united Tadeusz Kantor's relation with the Spanish
\end{abstract}


culture. They are mostly focused on the Spanish pictorial motifs in the visual arts and theatrical work by the Polish artist. Then, the article compares the impossible theater of García Lorca with the impossible theater of Kantor on the thematic level, but mainly on the aesthetic level focusing on the role that the objects play in both scenarios. They appear to be taken from the established system of signs and they become incomprehensible and unusual. In particular, there are two objects compared in Wielopole, Wielopole and in El Público, respectively. They are two rotating beds that at the same time are mortuary beds. Their symbolism and significance are analyzed in separate scenes and whole plays.

Keywords: Kantor, Garía Lorca, theater, surrealistic objects, double

Pod koniec mojej twórczości dodałem to drugie słowo: MIŁOŚĆ. ŚMIERĆ i MIEOŚĆ, trzeba je przyjąć obydwie (Kantor, 2004: 45) ${ }^{1}$

La bibliografía crítica de la obra de Tadeusz Kantor es muy amplia e internacional. De entre los muchísimos libros, artículos o ponencias pronunciadas en diversos congresos y seminarios, hay también muchos trabajos de corte comparativo que registran las influencias mutuas o testimonian las relaciones diversas. De hecho se han analizado varios elementos que unen a Kantor tanto con los escritores o directores polacos como por ejemplo Wyspiański, Schulz, Witkacy, Gombrowicz o Gorotowski, como con los artistas extranjeros como Joseph Beuys, Anselm Kiefer, Christoph Schlingensief, Christian Boltanski, Edward Gordon Craig y muchos otros más. Entre los artistas extranjeros aparecen obviamente también los españoles. No he encontrado muchos trabajos que reflexionen sobre tal relación (es decir Kantor y la cultura española), pero de los que disponemos, la inmensa mayoría señala los motivos pictóricos españoles en la obra

1 “Al final de mi trayectoria añadí esta segunda palabra: AMOR. MUERTE y AMOR hay que aceptar los dos" (traducción mía). 
tanto plástica como teatral del artista polaco. Aquí podemos enumerar un artículo de Judyta Wachowska titulado “¿Cómo se encontraron los mundos de la imaginación de Velázquez, Goya y Tadeusz Kantor? Sobre la circunstancia y la vocación" (Wachowska, 2007: 787-793), que versa sobre la presencia de los motivos de Velázquez y de Goya en los espectáculos teatrales de Kantor, todo en el contexto de las reflexiones de Ortega y Gasset contenidas en los famosos Papeles sobre Velázquez y Goya, un artículo además pronunciado en Cracovia, hace más de una década en el congreso Retos del hispanismo en la Europa Central y del Este. Sobre las influencias de la pintura española en la obra de Kantor reflexiona también Małgorzata Lisiewska en un trabajo escrito en polaco "Hiszpania - estetyczne inspiracje Tadeusza Kantora" (Lisiewska, 2006: 335-340). Un nuevo estudio dedicado al mismo tema lo ha presentado también últimamente Małgorzata Paluch-Cybuska de Cricoteca, Centro de la Documentación del Arte de Tadeusz Kantor, en el seminario internacional organizado en octubre de 2015, con ocasión del centenario del nacimiento del artista, por el Departamento de Filología Eslava de la Universidad Complutense de Madrid e impreso con el título polaco „Tadeusz Kantor: ...Infantki Velázqueza jak relikwie lub madonny" en el libro Dziś Tadeusz Kantor! Metamorfozy śmierci, pamięci i obecności (Paluch-Cybuska, 2014: 125-147). Una variante de este motivo pictórico español en la obra de Kantor y de otro escenógrafo y director polaco, Jan Polewka, la constituye también el trabajo de Violetta Sajkiewicz titulado „Malarstwo w teatrze. Motywy hiszpańskie w twórczości Tadeusza Kantora i Jana Polewki” (Sajkiewicz, 2002: 363-371).

Existe finalmente un bonito álbum bilingüe preparado en 1999 por el Instituto Cervantes de Varsovia titulado Motivos españoles en la obra de Tadeusz Kantor centrado, por un lado, en las influencias de Velázquez y Goya en las obras plásticas de Kantor, y por otro lado, en los dibujos del artista del ciclo Diario de viaje, dibujos de muy diferentes paisajes españoles (la región de Alicante y Las Canarias, los alrededores de Bilbao y las playas mallorquinas) que nacieron a finales de los 80 cuando el teatro Cricot 2 hacía su gira por España. El álbum contiene también otro ciclo de dibujos conocido 
como Catedrales de Barcelona; cuasiobjetos y algunos de sus trabajos escenográficos. Recordemos aquí que Kantor todavía al principio de los años 50 fue autor de escenografía y vestuario de visibles influencias del cubismo para el espectáculo calderoniano El Alcalde de Zalamea preparado por Władysław Krzemiński en el Teatro de J. Słowacki en Cracovia. En 1955 y 1957 preparó también dos versiones de la escenografía y vestuario para La zapatera prodigiosa de Federico García Lorca, la primera en Katowice (Teatr Śląski im. S. Wyspiańskiego, dirección de Bolesław Smela) y la otra en Cracovia (Teatr Stary, dirección de Tadeusz Kantor y Marian Słojkowski). Especialmente la primera versión adquirió cierto renombre entre los comentadores de aquel entonces quienes veían en ella un importante viraje respecto al naturalismo reinante. Andrzej Wydrzyński en el periódico Przemiany hablaba de uno de los mayores logros artísticos del teatro polaco de postguerra y Wacław Kubacki en las páginas de la revista Teatr constataba que Kantor había realizado una lectura genial de Lorca (Wydrzyński, 1957: 7). A su vez, Zenobiusz Strzelecki, autor de una conocida monografía sobre la escenografía polaca, advertía que los proyectos de los vestuarios que podemos contemplar en la documentación fotográfica de esta primera versión se basaban visiblemente en la herencia del surrealismo (Strzelecki, 1963: 505). Si estamos ya en la década de los 50, vale la pena advertir que en agosto de 1956, Kantor presentó los planes del repertorio para el teatro Cricot 2 (que desgraciadamente no llegaron a ser realizados) entre los que, sin embargo, estaba todavía una obra española más, a saber, Noche de guerra en el Museo del Prado de Rafael Alberti.

Volviendo al álbum, éste contiene también proyectos y esbozos preparados por Kantor para la ópera Don Quijote de Jules Massenet en 1962 en Cracovia. Precisamente en este espectáculo se basa Katarzyna Osińska en una publicación más sobre las relaciones entre Kantor y la cultura española titulada „Don Kichot według Kantora: między realnością a fikcją” (Osińska, 2014: 109-123), una publicación un tanto diferente ya que no habla de la tradición pictórica en la obra del autor polaco, sino al contrario, de la presencia de la figura literaria española en la escenografía de la ópera, en los llamados 
“embalajes”, obras plásticas de Kantor, y en su espectáculo Que revienten los artistas. Un interesante trabajo de corte comparativo dedicado a la adaptación del motivo pictórico de Las Meninas de Velázquez al discurso dramático polaco y español preparó en 2009 Karolina Kumor interpretando principalmente la presencia del personaje de Kantor en la obra teatral La Infanta de Velázquez de Jerónimo López Mozo (Kumor, 2009: 155-177). De este mismo tema se ocupó también Julia Nawrot de la Universidad de Granada en el ya citado seminario internacional organizado por la Universidad Complutense de Madrid. De entre las ponencias pronunciadas allí había dos más que acercaban al arista polaco a los autores españoles: una de Ana María Gómez Valencia de la Universidad Colombiana del Valle sobre la puesta en escena de la memoria según Tadeusz Kantor y Juan Mayorga, y otra de Julio Vélez Sainz de la UCM sobre la influencia de Kantor en el director y dramaturgo español José Luis Alonso de Santos y la directora estadounidense Stacy Klein, fundadora de Double Edge Theatre. Al final también vale la pena mencionar los trabajos sobre la recepción de Kantor en España preparados por Josep Maria de Sagarra Àngel (Sagarra Àngel, 2010: 9-33; Sagarra Àngel, 2014: 109-123).

Me gustaría añadir a este tema sobre kantoriano un listado o registro de algunas similitudes, sin intención de señalar influencias o deudas, entre la obra teatral de Kantor, sobre todo su espectáculo Wielopole, Wielopole de 1980 y el surrealismo español, sobre todo el drama lorquiano (recordemos que ambos autores denominaron su obra teatral como "teatro imposible"; Lorca en 1936 habló, entre otros, sobre El Público y Kantor publicó su Manifiesto del Teatro Imposible en febrero de 1974), y un poco también la obra de Buñuel. Estas similitudes pueden darse a diversos niveles, a nivel temático - meditaciones sobre el tiempo, los recuerdos y la memoria o una continua reflexión sobre la forma y el papel del teatro o una atención especial a la muerte-, o a nivel estético que es el que me interesa más en este momento. Dicho de otra forma, se trata de advertir algunas de las similitudes en la imaginería teatral surrealista ya que - en contra de una de las tesis de Dominika Łarionow (Łarionow, 2015: 
13), una investigadora del teatro polaco según la cual Kantor actuaba en oposición a dicha corriente, creo que al artista polaco, que tantas veces reconoció su fascinación por la imaginación de Salvador Dalí (frases como "creo en la religión de Salvador Dalí", "Él es mi Dios"2 o su conocida foto ante la tumba del pintor en el museo de Figueres), le podemos inscribir en el surrealismo entendido no dogmáticamente como una escuela de vida breve y procedencia francesa, sino ampliamente como un género de imaginación, un proyecto ideológico y una práctica estética que dejó su huella en todo el siglo XX. Si nos detenemos en la pintura española, aunque el tema de Velázquez en Kantor ha sido ya, como acabamos de ver, muchas veces investigado y explorado, me gustaría añadir una pequeña observación . Kantor en las varias de sus visitas a Madrid iba siempre al Museo del Prado; su mujer, Maria Stangret, recordaba que por primera vez fueron allí a principios de los 60 en un viaje no oficial (MatkowskaŚwięs, 1999: 38). El artista polaco confesaba incluso: "Me gustaba mucho Velázquez, en El Prado volvía siempre a Velázquez y Goya, lo demás me interesaba muy poco". ${ }^{3}$ Se suele, con razón, advertir que lo que le fascinaba en la Infanta era lo artificial de su cabeza, su cuerpo pequeño y raquítico debajo de un ropaje grueso y solemne, unos gestos forzados, una mirada vacía y sepulcral, la actitud de una total indiferencia y además su condición de personaje completamente indefenso. Pero Kantor subrayaba también, lo cual no se suele recalcar tanto, que de Velázquez le gustaba asimismo su escala de colores muy limitada, decía: "hay solamente los grisáceos marrones

2 "Salvador Dalí tenía una imaginación que superaba la lógica y buscaba lo imposible. La materia era algo elástico para él. Dalí renunció a la tierra para alcanzar el cielo, aunque conservó siempre un pie en la tierra. La obsesión por ir más allá de cuanto le rodeaba le llevó a creer que era Dios. Eso es lo que siempre me ha fascinado de él. [...] Creo en la religión de Salvador Dalí y creo que tenía razón creyéndose Dios. Él es mi Dios: de la nada creó el mundo, su propio mundo artístico" (AA.VV, 1999: 144).

3 "Bardzo lubiłem Velazqueza, w Prado wracałem zawsze do Velazqueza i Goyi, reszta mało mnie obchodziła." (Porębski, 1997: 133). 
de diferente intensidad, profundos, superficiales...". Precisamente esta misma escala de colores la utiliza Kantor en casi todas sus obras teatrales cuyo ambiente resulta, entre otros, del monocromatismo, de un omnipresente gris, ora tirando a negro, ora tirando a marrón.

En este escenario gris Kantor coloca varios objetos. Solemos recordar a Kantor como autor de objetos, autor de la famosa silla, una escultura representada en una plaza pública de mi ciudad, Wroclaw, autor de los conocidos paraguas, introducidos en las obras llamadas emballage, autor de la figura de la infanta transformada primero en un bolso, luego en un elemento del vestuario y finalmente hasta en un personaje teatral, autor de varios objetos sacados de su contexto real o corriente y mudados a una realidad artística. Estos objetos son además capaces de desplazarse entre todos los ámbitos de arte que profesaba Kantor: entre su pintura, su escultura, su dibujo y su teatro. Vemos que Kantor entablaba una relación íntima con los objetos teatrales que creaba; no era un simple utilitarismo de una escena representada únicamente una vez. Él buscaba nuevos espacios para sus objetos teatrales, inventaba para ellos nuevos papeles. Pero al mismo tiempo, he aquí la paradoja, Kantor - lo afirma Ewa Domańska (Domańska, 2008: 20) — no quiere personalizar al objeto, no lo quiere convertir en una señal o un mensaje simbólico. Todo lo contrario, lo desea abstraer de las actividades humanas, aislarlo de las situaciones naturales, sacarlo del orden común y del sistema de signos establecido y rutinario. Presentarlo a solas y a secas para posibilitar su incorporación en el ámbito del arte. Le interesaban especialmente los objetos — como decía—“de realidad de rango inferior” (,realności niższej rangi”), objetos despreciados por la cultura elevada , los trastos , cacharros, despojos que despiertan en el público la compasión. Es una actitud surrealista por excelencia. Kantor coge sus despojos, su tabla, o su armario, o su maleta, o su saco para desnudarlos de la normalidad. Presentados así nos parecen incomprensibles, sin sentido

4 “To jego operowanie bardzo zawężoną gamą kolorystyczną, tam są właściwie tylko brązowane szarości o różnej głębi, głębsze, płytsze..." (Ibidem). 
y por consiguiente insólitos, extraños y al mismo tiempo crece su grado de materialidad.

Tanto en el espectáculo Wielopole, Wielopole, como en El Público lo que observamos en la escena es el mundo interior de sus autores, el mundo de la memoria de una infancia lejana del artista polaco y el mundo de los miedos y deseos ocultos en el subconsciente del dramaturgo español. El teatro se convierte en una máquina creadora de un espacio para la meditación exteriorizada sobre uno mismo: es la definición del teatro de Kantor de Marek Pieniążek (Pieniążek, 2005: 40) que encaja perfectamente con el teatro imposible de Federico García Lorca. Estos mundos interiores tienen su cronología especial, las frases, escenas o emociones no aparecen unas tras otras como en un eje temporal que va del pasado al futuro sino que aparecen mezcladas, unas continuamente vuelven y se repiten, otras vienen apenas esbozadas.

El espectáculo Wielopole, Wielopole empieza con un intento por parte del director, y más tarde de los gemelos, el tío Olek y el tío Karol, de amueblar el espacio remoto de antaño con un armario de ruedas, una mesa, unos sillones, una ventana, la puerta. Simultáneamente en la escena tenemos dos espacios más que tienen una dinámica diferente, su historia propia y que de momento parecen permanecer indiferentes frente a las gestiones de los tíos. Uno de ellos es el grupo de soldados de las Legiones Polacas a las que pertenecía el padre de Kantor y otro lo constituye una cama con ruedas. Esta cama ocupa el espacio central, con ella empieza y finaliza el espectáculo. Es una cama simple, primitiva, rústica, típica de la cabaña del campo del siglo XIX, con el marco y el respaldo hechos de metal y en lugar de un colchón tiene un tablero. Lo especial de esta cama consiste en una manivela situada en el respaldo a los pies de la cama que posibilita elevar el tablero-colchón y hacerla girar. La cama efectivamente gira algunas veces durante el espectáculo presentando al cura, al tío José o a un maniquí que es su doble. Un objeto similar lo encontramos en el teatro surrealista español. El cuarto cuadro de El Público lorquiano empieza con la siguiente acotación: "En el centro de la escena, una cama de frente y perpendicular, como pintada por un primitivo, donde 
hay un Desnudo Rojo coronado de espinas azules. Al fondo, unos arcos y escaleras que conducen a los palcos de un gran teatro. A la derecha, la portada de una universidad. Al levantarse el telón se oye una salva de aplausos" (García Lorca, 1996: 311). En el momento de la muerte del Desnudo, la acotación precisa: "la cama gira sobre su eje y el Desnudo desaparece. Sobre el reverso del lecho aparece tendido el Hombre 1o, siempre con frac y barba negra" (Ibidem: 316). Tenemos así dos camas giratorias. Ambas además son lechos de muerte . En la cama de Kantor el maniquí está muriendo. Su muerte la espera impacientemente la viuda del fotógrafo local que interrumpe varias veces para sacar la foto del recién muerto y luego limpiarlo. Le retiene la abuela Katarzyna que ejerce de enfermera, está a la cabecera con un orinal y canta las canciones religiosas típicas del oficio de vísperas, más concretamente el salmo 110 . Una vez muerto la viuda gira la cama y aparece el cura verdadero. Esta escena volverá al final del espectáculo. A la muerte del cura asistirá la familia, una parte de los familiares repite los rezos de "santo, santo, santo", la otra no lo reconoce, están buscando al tío verdadero haciendo girar la manivela y reconociendo a su familiar en el maniquí. Finalmente el maniquí, como Cristo, será clavado en la cruz.

También en Lorca asistimos primero a la muerte del Desnudo. El Desnudo rojo coronado con espinas azules, quizá relacionado con el Cristo del famoso cuadro de El Greco titulado El expolio, representación del momento inicial de la Pasión en el que observamos a Cristo vestido con una túnica de color rojo intenso que resalta sobre el resto . A su muerte asiste, como la abuela Katarzyna en Kantor, el Enfermero. El moribundo, interesado por lo que pasa con el director del teatro y con Gonzalo, así como por el desarrollo de la revolución nacida a raíz de una audaz representación de Romeo y Julieta llevada a cabo por "el teatro bajo la arena", tiene unas connotaciones bíblicas obvias: el enfermero le da la hiel, él mismo pronuncia las frases como "Padre mío, aparta de mí este cáliz de amargura" o "Padre mío, perdónalos, que no saben lo que hacen". En el momento de la muerte dos ladrones sentados a los pies de la cama mortuoria levantan los cirios y repiten la jaculatoria "santo, santo, santo". Vemos así que ambas 
muertes por duplicado, la del cura-tío Józef y su doble (cuya figura está basada en el personaje auténtico del padre Józef Radoniewicz en cuya parroquia Kantor vino al mundo), como la del Desnudo Rojo y el Hombre $1^{\circ}$, también su doble, son las muertes de Cristo crucificado, son muertes por amor. Simultáneamente a la agonía del Desnudo Rojo transcurre la escena de las damas y los estudiantes que, al igual que en Kantor, una vez más, no se entrecruza con la del Desnudo. Puede ser debido a que a los partidarios del teatro burgués no les interesa la muerte de su oponente, puede ser también que se trate de otro nivel ya que para muchos de los investigadores El Público se desarrolla simultáneamente en el mundo subconsciente del Director poblado por Caballos, Hombres y sus dobles y en el plano real del espectáculo shakespeariano poblado por actores y el público, es decir, damas y estudiantes. El hombre $1^{\circ}$ que en los cuadros anteriores destacaba por la autenticidad amorosa, que persuadía al Director de que el amor puede darse no solamente entre el hombre y la mujer, ya que "Romeo puede ser un ave y Julieta puede ser una piedra", muere también al final de la escena con un grito débil llamando a Enrique.

Como estamos viendo, tanto Kantor como Lorca, ya sea en las dos obras analizadas como en muchas otras suyas, rompen el monopolio de sus personajes teatrales, cortan en pedazos pequeños su identidad al presentar el original del personaje y su proyección, su doble, su copia muchas veces de cuerpo artificial. A los surrealistas este tipo de dobles les gustaban mucho. Se suele valorar la famosa imagen doble inventada por Salvador Dalí, es decir, los cuadros que sin necesidad de hacer cualquier cambio pueden representar simultáneamente dos o más objetos o fenómenos, como el retrato de la actriz Mae West y al mismo tiempo unos muebles extravagantes. El original y su doble enfrentados en un duelo de pistolas aparecen también en una escena de El perro andaluz del dúo Luis Buñuel-Salvador Dalí. En El Público los originales de los personajes se dividen en los trajes autónomos y se multiplican tanto que sus búsquedas de las formas primarias y básicas resultan poco exitosas. Se oyen continuamente las voces que llaman “¡Enrique!” o pregonan “¡Elena!”. En Kantor también continuamente el tío Olek busca al tío Karol, o al revés, voceando sus 
respectivos nombres. El mundo parece ser así un juego de apariencias en el que no podemos estar seguros ni de nuestros recuerdos, ni de nuestras emociones. Miriam Balboa Echeverría (Balboa Echeverría, 1980: 151) llama la atención de que en el drama lorquiano los protagonistas buscan desesperadamente su identidad dentro del mundo de las formas vacías o las formas preparadas de antemano que nos absorben como un agujero negro. Los maniquís que hacen vacilar sobre la estabilidad del "yo" constituyen el elemento central del manifiesto titulado El Teatro de la Muerte de Kantor donde leemos: "De pronto empiezo a interesarme por la naturaleza de los MANIQUÍS / El MANIQUÍ como un objeto vacío, como un reclamo".5 Tanto en Wielopole, Wielopole, como en El Público tenemos formas vacías, e incluso los trajes vacíos (en Kantor en la última escena entra en una silla de ruedas el traje vacío de un soldado) que parecen simbolizar los recuerdos, la memoria persistente de lo que ha sido, los restos de la conciencia. En Kantor y en Lorca los dobles artificiales, los doble maniquís están vacíos y tiesos y los originales empiezan a imitar a sus dobles, con los gestos, los movimientos y las palabras igual de inertes y rígidas. Se puede leer este gesto también como una actitud surrealista por excelencia ya que los surrealistas querían terminar con el mundo binario y definido por las continuas antinomias, también les gustaba borrar el límite entre los seres vivos y los muertos, los orgánicos y los artificiales. Deseaban encontrar lo que está entre estos dos polos. El mismo Kantor se situaba a sí mismo también en un espacio de "entre", entre el límite de la escena y el límite del público.

Al final, y para terminar, me gustaría mencionar tan sólo que la última escena de Wielopole, Wielopole por lo blasfemo y por lo grotesco guarda también cierto paralelismo con un famoso fragmento final de la película Viridiana de Luis Buñuel cuando los mendigos, algunos también vestidos de novia, se sientan a la mesa formando una imitación de la conocida pintura mural de Leonardo da Vinci. Por un momento quedan inmóviles porque una compañera les quiere hacer

5 "Ni stąd ni zowąd zaczynam się interesować naturą MANEKINÓW. (...)/ MANEKIN jako przedmiot pusty, atrapa” (Kantor, 2004: 17). 
una foto. Kantor no es tan literal, pero a su mesa cubierta por un mantel blanco se sientan también un judío, los novios, los familiares y detrás, a sus espaldas, estamos viendo a un maniquí del cura crucificado. Se quedan inmóviles para posibilitar a La viuda del fotógrafo sacar una foto. El público observa ambas "últimas cenas" desde la misma perspectiva horriblemente grotesca en Buñuel y horriblemente trágica en Kantor.

\section{Bibliografía}

AA.VV. (1999), Motivos españoles en la obra de Tadeusz Kantor. Motywy hiszpańskie w twórczości Tadeusza Kantora, Instituto Cervantes de Varsovia, Varsovia.

BALBOA ECHEVERRÍA, M. (1980), La visión paralizante: el surrealismo en el teatro de Federico García Lorca, a dissertation submitted in partial fulfillment of the requirements for the degree of Doctor of Philosophy, University of Washington, Washington.

DOMAŃSKA, E. (2008), "Humanistyka nie-antropocentryczna a studia nad rzeczami”, Kultura Wspótczesna, 3, Warszawa, pp. 9-21.

GARCÍA LORCA, F. (1996), El Público, en: Obras completas, ed. de García-Posada, M., t. 2, Teatro, Galaxia Gutenberg / Círculo de Lectores, Barcelona, pp. 279-327.

KANTOR, T. (2004), LE THÉÂTRE DE LA MORT ET DE L'AMOUR, en: Teatr Cricot 2. Informator 1989-1990, wyb. i oprac. A. Halczak, Cricoteca, Kraków.

KANTOR, T. (2004), Teatr Śmierci. Teksty z lat 1975-1984, en: Pisma, t. 2 , wyb. i oprac. K. Pleśniarowicz, Ossolineum, Wrocław.

KUMOR, K. (2009), “Moja Infantka, Velázqueza, ale moja! O migracji motywu malarskiego i dialogu międzykulturowym: Diego Velázquez, Tadeusz Kantor i Jerónimo López Mozo", en: Aszyk, U., Flisek, A., Grützmacher, Ł., Kumor, K. (eds.), W kręgu literatury i kultury iberyjskiej i iberoamerykańskiej. Migracja i transformacja dyskursów - dialog międzykulturowy, Wydawnictwa Uniwersytetu Warszawskiego, Warszawa, pp. 155-177. 
LISIEWSKA, M. (2006), "Hiszpania - estetyczne inspiracje Tadeusza Kantora”, en: Jagłowski, M., Sepczyńska, D., (red.), Z myśli hiszpańskiej i iberoamerykańskiej. Filozofia, literatura, mistyka, Instytut Cervantesa w Warszawie, Instytut Filozofii UWM w Olsztynie, Katedra UNESCO UWM w Olsztynie, Wydział Socjologii i Pedagogiki WSIiE TWP w Olsztynie, Olsztyn, pp. 335-340.

ŁARIONOW, D. (2015), Wystarczy tylko otworzyć drzwi... Przedmioty w twórczości Tadeusza Kantora, Wydawnictwo Uniwersytetu Łódzkiego, Łódź.

MATKOWSKA-ŚWIĘS, B. (1999), "Tadeusza Kantora dialog z Hiszpanią”, Wysokie Obcasy, 124, 29-30.05, Warszawa, pp. 38-39.

OSIŃSKA. K. (2014), “Don Kichot według Kantora: między realnością a fikcją”, en: Bryś, M., Burzyńska, A.R., Fazan, K. (red.), Dziś Tadeusz Kantor! Metamorfozy śmierci, pamięci i obecności, Wydawnictwo Uniwersytetu Jagiellońskiego, Kraków, pp. 109-123.

PALUCH-CYBULSKA, M. (2014), "Tadeusz Kantor: ...Infantki Velázqueza jak relikwie lub madonny”, en: Bryś, M., Burzyńska, A.R., Fazan, K. (red.), Dziś Tadeusz Kantor! Metamorfozy śmierci, pamięci i obecności, Wydawnictwo Uniwersytetu Jagiellońskiego, Kraków, pp. 125-147.

PIENIĄŻEK, M. (2005), Akt twórczy jako mimesis. „Dziś sa moje urodziny” - ostatni spektakl Tadeusza Kantora, Universitas, Kraków.

PORĘBSKI, M. (1997), T. Kantor. Świadectwa. Rozmowy. Komentarze, Murator, Warszawa.

SAGARRA ÀNGEL de, J.M. (2010), "Infantas, soldados, rinocerontes y otros personajes kantorianos. A propósito de los motivos españoles en la obra de Tadeusz Kantor”, en: Bravo García, F. (ed.), Reeler a Tadeusz Kantor. 1990-2010, Casa de L'Est, Barcelona, pp. 9-33.

SAGARRA ÀNEGEL de, J.M. (2014), “Teatr emocji Tadeusza Kantora. $A$ propos hiszpańskiej recepcji artysty”, en: Bryś, M., Burzyńska, A.R., Fazan, K. (red.), Dziś Tadeusz Kantor! Metamorfozy śmierci, pamięci i obecności, Wydawnictwo Uniwersytetu Jagiellońskiego, Kraków, pp. 109-123.

SAJKIEWICZ, V. (2002), "Malarstwo w teatrze. Motywy hiszpańskie w twórczości Tadeusza Kantora i Jana Polewki”, en: Rusek, H. (red.), 
Dawne i współczesne oblicze kultury europejskiej-jedność w różnorodności, Wydawnictwo Uniwersytetu Śląskiego, Katowice, pp. 363-371. STRZELECKI, Z. (1963), Polska plastyka teatralna, Państwowy Instytut Wydawniczy, Warszawa.

WACHOWSKA, J. (2007), “Cómo se encontraron los mundos de imaginación de Velázquez, Goya y Tadeusz Kantor? Sobre la circunstancia y la vocación", en: Cercós García, L.F., Molina Rivero, C.J., Ceballos-Escalera Gila, A. de (coord.), Retos del Hispanismo en la Europa Central $y$ del Este. Actas del Congreso Internacional Cracovia 14-15 de octubre de 2005, Palafox \& Pezuela, Madrid, pp. 787-793.

WYDRZYŃSKI, A. (1957), „Sztuka pozaplanowa”, Przemiany, 15, 14 IV, p. 7. 